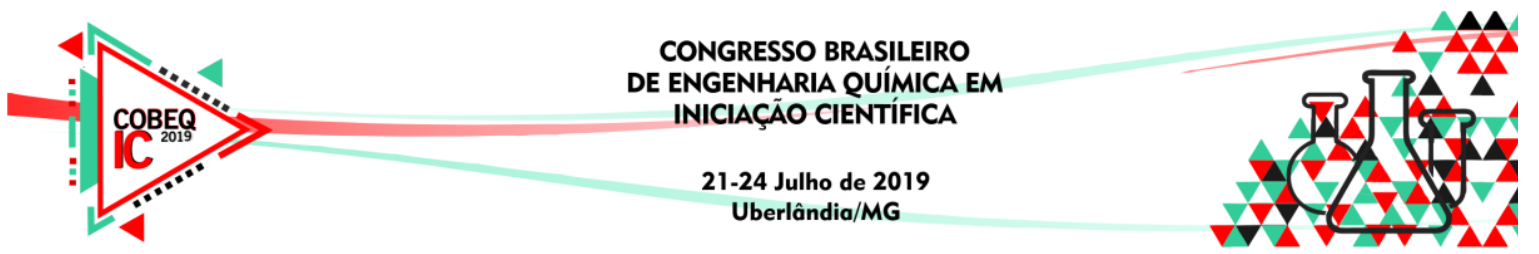

\title{
SIMULAÇÃO DO PROCESSO DE TRATAMENTO DE ESGOTO DOMÉSTICO DE UMA ETE MUNICIPAL DA CIDADE DE VASSOURAS/RJ
}

\author{
I. M. M. NEVES ${ }^{1}$, E. B. MARRA ${ }^{1}$, T. S. SANTANA ${ }^{1}$, M. T. MADUREIRA ${ }^{1}$, e C.S.S. \\ PEREIRA $^{1}$ \\ ${ }^{1}$ Universidade de Vassouras, Curso de Engenharia Química \\ E-mail para contato: isabella.munizmn@gmail.com
}

\begin{abstract}
RESUMO - O crescimento populacional tem contribuído para o aumento de carga de efluentes domésticos que são gerados causando graves problemas de saúde na população e um grande impacto ambiental. O tratamento de esgoto é uma medida de saneamento básico tendo como objetivo acelerar o processo de tratamento da água. O presente trabalho avalia a simulação de uma estação de tratamento de esgoto (ETE) utilizando o simulador de processo ProSimPlus@, considerando um sistema compatível com o de lodos ativados. Através do uso de simuladores é possível gerenciar um processo de forma a melhorar a eficiência de uma planta e assim prever e reduzir os potenciais impactos que possam vir a ser acometidos. Para a simulação, utilizaram-se os parâmetros de entrada baseados em uma ETE compacta do município de Barra do Piraí/RJ. A ETE em questão realiza o tratamento de esgoto com uma vazão de $26,40 \mathrm{~m}^{3} / \mathrm{h}$ compreendendo as etapas de captação, tratamento primário, tratamento em reator aeróbico por lodo ativado e sedimentação. Considerando o processo de oxidação biológica por lodo ativado, verificou-se após o balanço de massa da simulação a degradação da glicose como principal matéria orgânica presente no tratamento. Conclui-se que a aplicação do software foi satisfatória em relação à simulação de uma estação de tratamento de esgoto.
\end{abstract}

\section{INTRODUÇÃO}

A Política Nacional de Saneamento, instituída pela Lei Federal no 11.445, de 2007, define saneamento básico como o conjunto de serviços, infraestruturas e instalações de abastecimento de água, esgotamento sanitário, limpeza urbana e manejo de resíduos sólidos e drenagem de águas pluviais urbanas. $\mathrm{O}$ tratamento de esgoto é uma medida de saneamento básico e tem como objetivo acelerar o processo de purificação da água. As unidades de tratamento utilizam processos químicos e biológicos para decomposição da matéria orgânica (Von Sperling, 2005).

Jordão e Pessôa (2011) evidencia que, lodo ativado é o floco produzido no esgoto bruto ou decantado pelo crescimento de bactérias zoogléias ou outros organismos, na presença de oxigênio dissolvido, e acumulado em concentração suficiente graças ao retorno de outros flocos previamente formados. O método de tratamento por lodo ativado consiste no tratamento estritamente biológico e aeróbico do efluente, utilizado na situação em que é necessária uma 


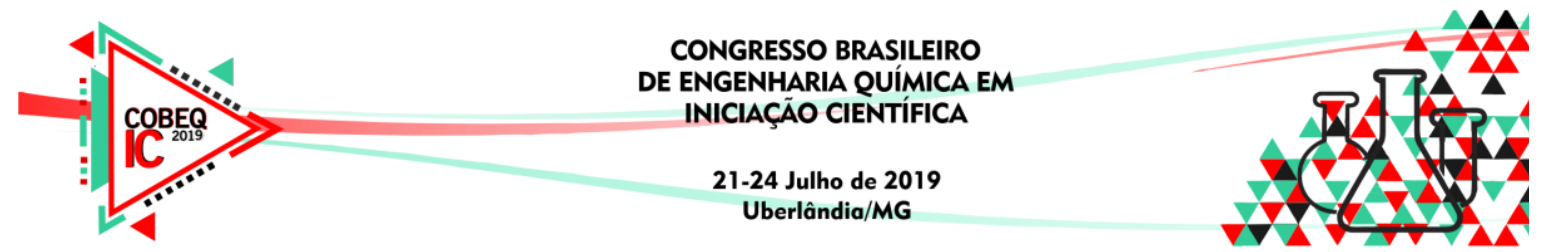

elevada qualidade do efluente em espaços reduzidos de área e tratar grandes despejos domésticos e industriais (Von Sperling, 2012).

De acordo com Santos (2018), o processo consiste na degradação da matéria orgânica, por bactérias aeróbias, dentro do tanque de aeração, no qual é introduzido excesso de oxigênio. Na sequência o efluente é dirigido para o decantador. Parte do lodo decantado retorna ao tanque de aeração como forma de reativação da população de bactérias. Este retorno se dá na entrada do tanque onde o lodo em fase endógena se mistura ao efluente rico em poluente, aumentando assim a eficiência do processo. A outra parte retirada sai estabilizada e pode ser destinada para outra finalidade.

Segundo Strieder (2010), os simuladores de processo têm um papel importante no âmbito da Engenharia Química, facilitando o aprendizado permitindo a simulação de diferentes cenários industriais. Dentro desta temática, cita-se o simulador de processos ProSimPlus ${ }^{\circledR}$ utilizado para predição e análise em balanços de massa e energia. Este software é empregado na melhoria de projetos, aumentando a eficiência da planta e reduzindo impactos ambientais. Aliado a isso, destaca-se também como uma importante ferramenta para atividades acadêmicas dentro das disciplinas de Engenharia.

Na literatura, poucos são os relatos de trabalhos com simulação de processo para estações de tratamento de esgoto, em especial cita-se a ausência deste tipo de simulação (ETE) na base de dados do software ProSimPlus ${ }^{\circledR}$. Diante do exposto, o presente trabalho tem como objetivo simular o processo de tratamento de esgoto a partir do processo de lodo ativado comparando com dados reais de uma estação de tratamento de esgotos municipal.

\section{MATERIAS E MÉTODOS}

Para a simulação do processo foram considerados como dados de entrada no simulador informações fornecidas por uma estação de tratamento de esgoto compacta que atende duas mil pessoas. A ETE opera a uma vazão de projeto de $26,40 \mathrm{~m}^{3} / \mathrm{h}$.

Diante dos parâmetros reportados por Jordão e Pessôa (1995), destaca-se uma composição do esgoto de $70 \%$ de sólidos compostos por matéria orgânica, proteínas, carboidratos, gorduras e óleos e 30\% de matéria inorgânica formada, principalmente, pela presença de areia e de substâncias minerais dissolvidas.

Para a simulação, foram utilizados dois compostos representativos da parte majoritária do efluente, sendo eles: o ácido palmítico que é um dos ácidos graxos mais comuns, e a glicose como parte da matéria orgânica. Para a elaboração do fluxograma de processo da estação, seguiu-se as seguintes etapas:

Processo de captação de água: considerou-se o processo de adução por recalque, sendo representado no simulador por uma bomba centrífuga.

Gradeamento: para a representação da remoção dos sólidos grosseiros através do gradeamento considerou-se um filtro prensa denominado por Plate frame filter. 


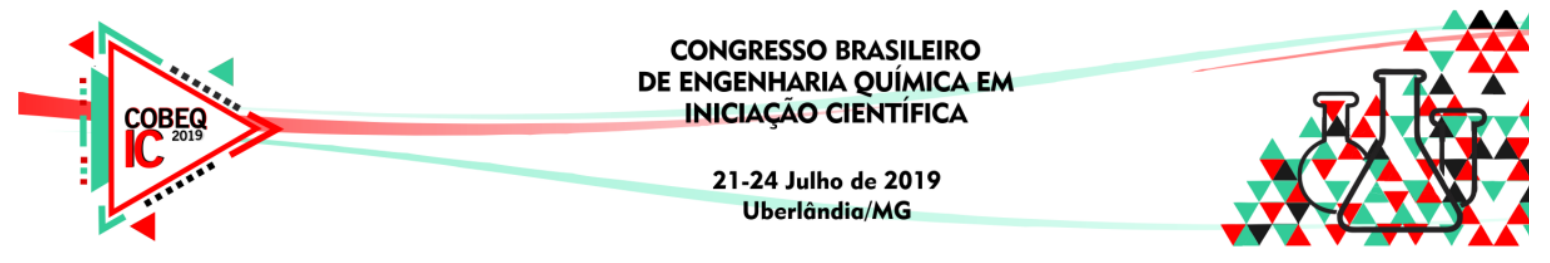

Processo biológico: para a decomposição da matéria orgânica considerou-se o processo de lodo ativado sendo representado no simulador por um reator denominado Reaction Tank.

Simplificadamente devido a representação de $50 \%$ do total da matéria orgânica, considerou-se na simulação considerou-se na simulação apenas a reação de oxidação da glicose, de acordo com a Reação 1. Essa energia liberada é responsável pela formação de novos microrganismos, que dão continuidade ao processo de lodo ativado.

$$
\mathrm{C}_{6} \mathrm{H}_{12} \mathrm{O}_{6}+6 \mathrm{O}_{2} \rightarrow 6 \mathrm{CO}_{2}+6 \mathrm{H}_{2} \mathrm{O}+\text { Energia }
$$

No simulador a cinética da reação empregada no reator é representada pelas Equações 2, 3 e 4 citadas abaixo.

$$
\begin{gathered}
\sum_{j=1}^{N C} V_{i . j} * R_{j} \stackrel{k_{j}}{\rightarrow} \sum_{j=1}^{N C} V_{i . j}^{\prime} * P_{j} \\
\frac{1}{\sum_{\boldsymbol{U}_{\boldsymbol{t}} \boldsymbol{U}_{\boldsymbol{c}} \boldsymbol{i}=\mathbf{1}}^{N_{\boldsymbol{1}}} \propto_{\boldsymbol{j}, \boldsymbol{i}^{-1}}}
\end{gathered}
$$

Onde: $\mathrm{R}$ é o reagente, $\mathrm{P}$ produto, $\mathrm{V}_{\mathrm{ij}}$ coeficiente estequiométrico do reagente na reação $i, V_{i, j}$ coeficiente estequiométrico do produto na reação i, NC número de componentes, i é o índice do componente e j índice da reação química.

$$
r_{j}=k_{j}^{0} * e^{\left(-\frac{E a_{j}}{R T}\right)} * \prod_{i=1}^{N C} A_{i}^{\alpha_{i j}}
$$

Onde: $\mathrm{Ea}_{\mathrm{j}}$ energia de ativação da reação $\mathrm{j}, \mathrm{R}$ constante dos gases perfeitos, $\mathrm{T}$ temperatura, $\mathrm{k}_{\mathrm{j}} 0$ é o fator de frequência da reação $\mathrm{j}, \propto_{\mathrm{i}, \mathrm{j}}$ ordem parcial do componente i na reação j e $A_{i}$ fração molar ou concentração do componente $i$.

Sedimentação: após o processo biológico de decomposição da matéria orgânica o efluente segue para o decantador. Este foi representado pelo clarificador. A Figura 1 apresenta o fluxograma do processo completo simulado. 
Figura 1 - Fluxograma proposto através do simulador ProSimPlus ${ }^{\circledR}$.

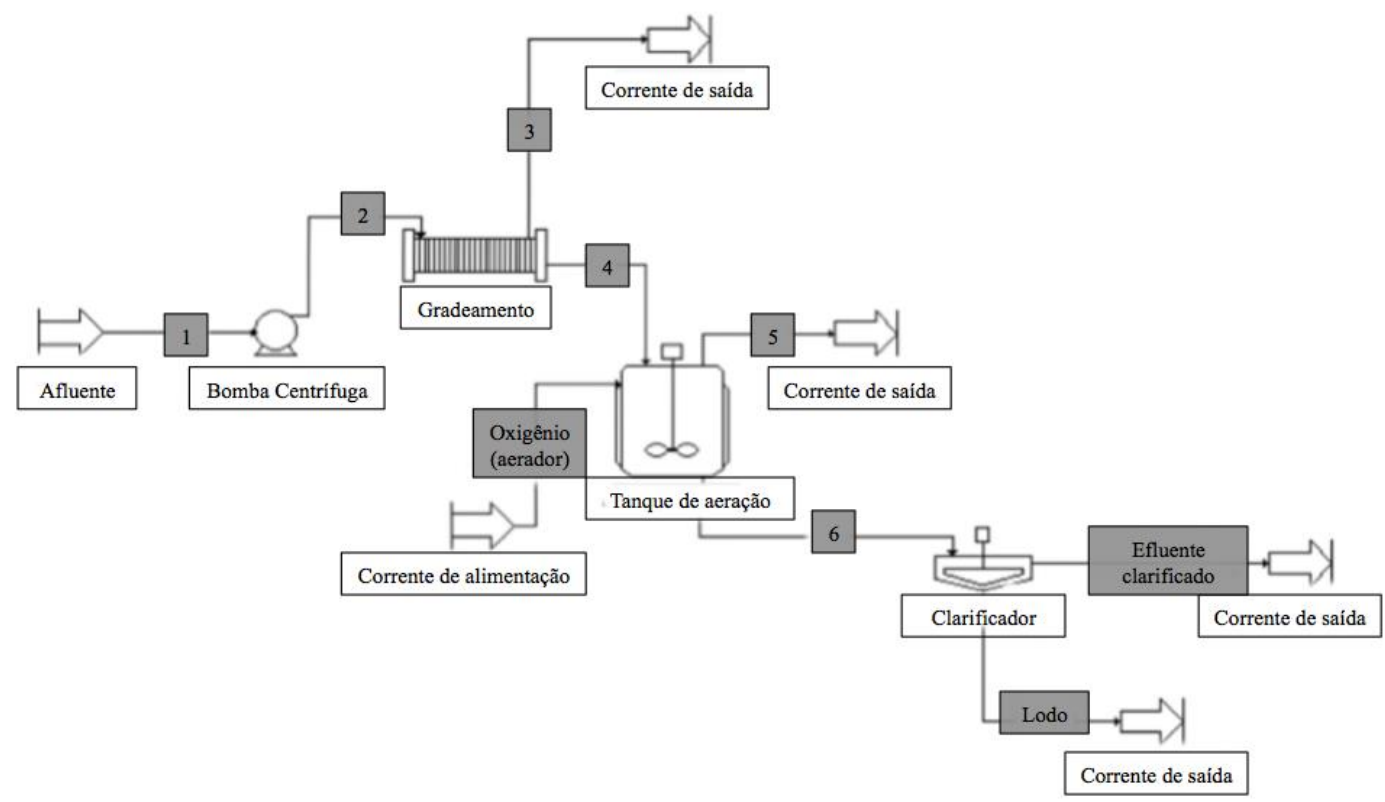

\section{RESULTADOS E DISCUSSÕES}

A Tabela 1 apresenta o balanço de massa de todas as correntes do processo simulado, que consiste basicamente de fluxos de massa de entrada e saída.

Tabela 1 - Balanço de massa do processo de simulação da ETE (L/h)

\begin{tabular}{|c|c|c|c|c|c|c|c|c|}
\hline \multirow{2}{*}{ 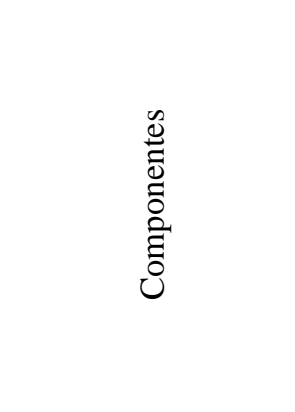 } & 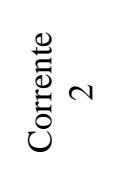 & 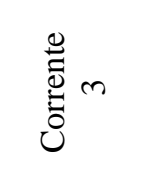 & 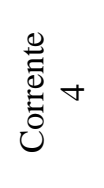 & $\begin{array}{l}n \\
0 \\
0 \\
0 \\
0 \\
0\end{array}$ & $\begin{array}{l}0 \\
0 \\
0 \\
0 \\
0 \\
0\end{array}$ & 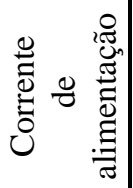 & 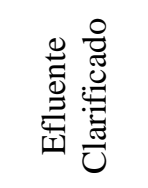 & 足 \\
\hline & 总 & 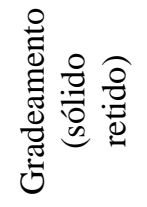 & 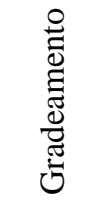 & 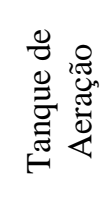 & 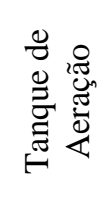 & 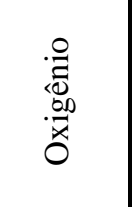 & 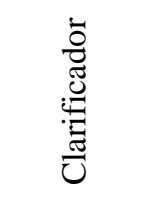 & 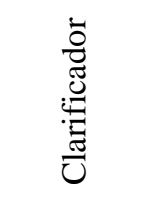 \\
\hline Água & 25966 & 0,82 & 25965 & 1,54 & 25969 & 0 & 25969 & $8,8 \mathrm{E}-6$ \\
\hline Ácido Palmítico & 1,07 & 0,82 & 0,09 & 0 & 0,09 & 0 & 2,34E-03 & $\mathbf{0 , 0 9}$ \\
\hline Oxigênio & 156,42 & 7,05E-06 & 0,22 & 448,89 & 42,63 & 500 & 42,63 & $1,45 \mathrm{E}-08$ \\
\hline Dióxido de Carbono & 0 & 0 & 0 & 3,03 & 8,96 & 0 & 8,96 & $3,05 \mathrm{E}-14$ \\
\hline Glicose & 5,90 & $1,86 \mathrm{E}-04$ & 5,91 & 0 & 0,59 & 0 & $\mathbf{0 , 5 9}$ & $2,10 \mathrm{E}-10$ \\
\hline
\end{tabular}

Fonte: Elaborada pelos autores. 


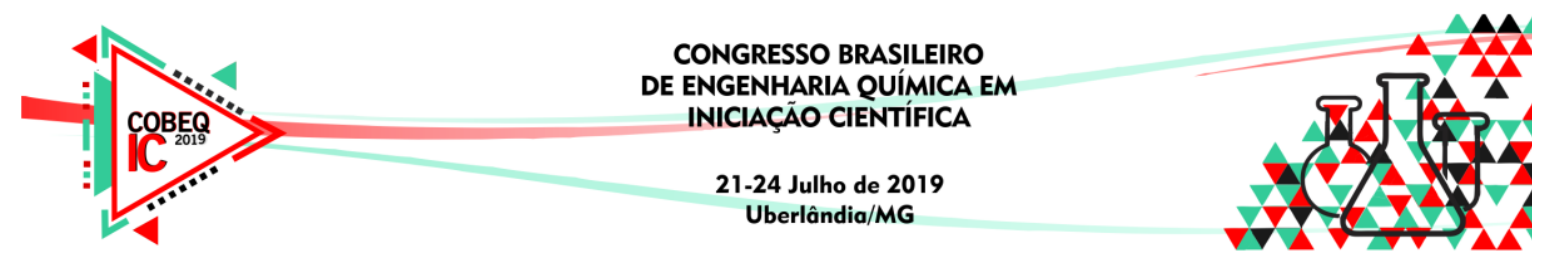

O ácido palmítico e a glicose apresentados na tabela, onde demonstraram um consumo de $99 \%$ e $90 \%$ no reator. Além do alto consumo de ácido palmítico, observou-se maior retenção deste parâmetro na corrente de lodo em comparação com a corrente de efluente clarificado.

Apesar da apresentação de consumo e retenção do ácido palmítico, verificou-se uma maior quantidade de glicose na corrente de efluente clarificado, neste caso a retenção deste parâmetro na corrente de lodo foi insatisfatória. Necessitando portanto de novos estudos para ajustes dos dados.

A eficiência dos resultados também pode ser observada através da perda insignificativa de água durante o processo. Já o oxigênio ocorreu um consumo de $73 \%$ no efluente clarificado, que é necessário para que ocorra a reação, no sistema de aeração. A geração de dióxido de carbono, indicada na corrente 5 , pode ser verificada devido a reação 1 , que ocorre no reator.

Desta maneira, o software ProSimPlus@ foi satisfatório em relação à simulação de uma estação de tratamento de esgoto, mesmo que seja mais utilizado em outras áreas da engenharia química como: destilação, separação, entre outros.

\section{CONSIDERAÇÕES FINAIS}

De acordo com os resultados obtidos, conclui-se que a proposta de simulação de uma ETE no ProSimPlus@ é de grande interesse, devido à ausência de dados na literatura sobre a simulação do processo. É necessário um aprofundamento dos parâmetros de simulação com dados de operações reais, a fim de demonstrar a efetividade e o valor do uso da ferramenta na descrição e aperfeiçoamento do processo de tratamento.

Para estudos futuros é proposta a adição de novas reações que ocorrem no processo de lodo ativado na simulação. Simulações deste tipo possibilitam uma representação real dos processos permitindo o desenvolvimento de novos projetos. A continuação do projeto se faz necessário para melhor representação do efluente doméstico e ajustes de parâmetros no simulador ProSimPlus@.

\section{REFERÊNCIAS}

BRASIL. Lei $\mathrm{n}^{\circ} 11.445$, de 5 de janeiro de 2007. Estabelece diretrizes nacionais para o Saneamento Básico. Disponível em: <https://www2.camara.leg.br/legin/fed/lei/2007/lei11445-5-janeiro-2007-549031-normaatualizada-pl.pdf>. Acesso em: 24 fev. 2019.

JORDÃO, E. P., \& PESSÔA, C. A. Tratamento de esgotos domésticos. 3 ed. Rio de Janeiro: ABES, 1995.

JORDÃO, E. P., \& PESSÔA, C. A. Tratamento de esgotos domésticos. 6 ed. Rio de Janeiro: ABES, 2011. 


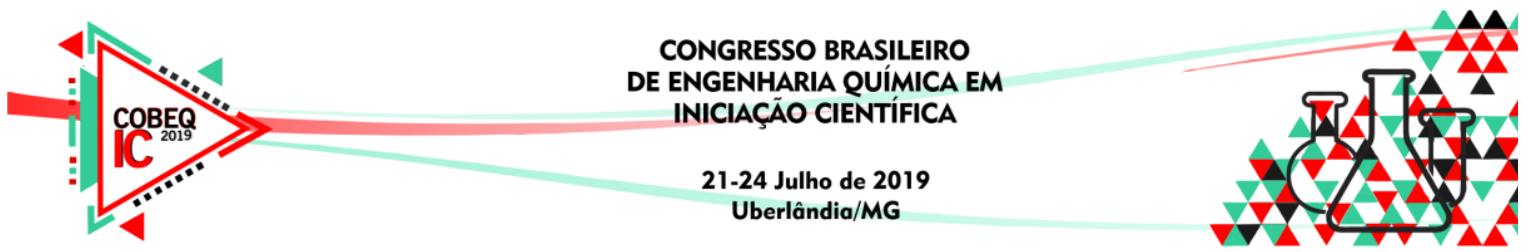

KOYASHIKI, R. S. Determinação da atividade aeróbia específica de lodo ETE por respirometria. 10p. Trabalho de Conclusão de Curso. Graduação em Engenharia Ambiental. Universidade Tecnológica Federal do Paraná, Londrina - PR, 2016.

PROSIM. Chemical process simulation software and services - engineering process solutions and services. Disponível em: <http://www.prosim.net/fr/index.php>. Acesso em: 15 fev. 2019.

SANTOS, C. L.; BARBOSA, T.; JÚNIOR, R. S. F. Lodo ativado aeróbico: Uma Breve Abordagem. Revista conexão eletrônica, Três Lagoas - MS, v. 15, n. 1, jan. 2018.

STRIEDER, A.; SCHUCH, C. M.; FRIAS, A. R. Utilização de simuladores de processos como ferramenta para o ensino de Engenharia. Revista Unisal, [S.L], jan. 2010.

VON SPERLING, M. Introdução à qualidade das águas e ao tratamento de esgotos. Editora UFMG, 2005.

VON SPERLING, M. Lodos ativados, vol.4, $3^{\text {a }}$ edição. Editora UFMG, 2012. 